\title{
Computational Modeling of Residual Stress Formation during the Electron Beam Melting Process for Inconel 718
}

\author{
P. Prabhakar ${ }^{1 a}$, W.J. Sames ${ }^{\mathrm{b}}$, R. Dehoff ${ }^{\mathrm{d}}$, and S.S. Babu ${ }^{\mathrm{c}, \mathrm{d}}$ \\ ${ }^{a}$ Department of Mechanical Engineering, University of Texas, El Paso, TX \\ ${ }^{b}$ Department of Nuclear Engineering, Texas A\&M University, College Station, TX \\ ${ }^{c}$ Department of Aerospace and Biomedical Engineering, University of Tennessee, Knoxville, TN \\ ${ }^{d}$ Manufacturing Demonstration Facility, Oak Ridge National Laboratory, Knoxville, TN
}

\begin{abstract}
A computational modeling approach to simulate residual stress formation during the Electron Beam Melting (EBM) process within the Additive Manufacturing (AM) technologies for Inconel 718 is presented in this paper. The EBM process has demonstrated a high potential to fabricate components with complex geometries, but the resulting components are influenced by the thermal cycles observed during the manufacturing process. When processing nickel based superalloys, very high temperatures (approx. $1000^{\circ} \mathrm{C}$ ) are observed in the powder bed, base plate, and build. These high temperatures, when combined with substrate adherence, can result in warping of the base plate and affect the final component by causing defects. It is important to have an understanding of the thermo-mechanical response of the entire system, that is, its mechanical behavior towards thermal loading occurring during the EBM process prior to manufacturing a component. Therefore, computational models to predict the response of the system during the EBM process will aid in eliminating the undesired process conditions, a-priori, in order to fabricate the optimum component. Such a comprehensive computational modeling approach is demonstrated to analyze warping of the base plate, stress and plastic strain accumulation within the material, and thermal cycles in the system during different stages of the EBM process.
\end{abstract}




\section{Introduction}

Powder Bed Fusion is a specific category of Additive Manufacturing (AM) that forms parts layer-by-layer using a bed of metal powder and a heat source. Laser Melting (LM) uses a laser beam as the heat source and Electron Beam Melting (EBM) uses an electron beam. Recent research efforts have focused on developing Inconel 718, a nickel-based superalloy attractive material for aerospace and energy applications involving hightemperature applications, for production using $\operatorname{LM}[1,2,3,4]$ and $\operatorname{EBM}[5,2,6,7]$. The cost associated with machining and shaping Ni-based alloys can be reduced in some cases by using the EBM process [8].

Extensive work has been conducted by researchers for model development and material property characterization for laser AM process $[9,10,11,12,13,14,1,15,16]$ . Previous work on EBM Inconel 718 has focused on characterizing the as-fabricated and post-processed microstructure. Parts produced in these studies are typically removed from the build substrate, or base plate, for testing and analysis by metal saws or wire electro-discharge machining. The EBM build substrate is traditionally stainless steel, which forms a brittle interface with the commonly processed Ti-6Al-4V alloy [17]. The stainless steel interface with Inconel 718 is not brittle, which leads to interesting residual stress as well as the additional step of substrate removal.

The origin of residual stress in AM processes is due to either (1) differential heating of solid forming large thermal gradients or (2) differential cooling. Previous work [18] to experimentally quantify residual stress in the SLM process using an unheated build chamber has shown that residual stress is compressive near the center of parts and tensile at the edge. Additionally, measurements of parts adhered to the build plate showed concentration near the substrate interface [19]. Laser free formed material showed residual stress of $50-80 \%$ of the yield stress [20], whereas EBM material shows only $5-10 \%$ of UTS [21]. Substrate warping, or deformation during the AM build process, and its physical relationship to residual stress has been noted in LM [22]. 
There has been limited work to model substrate deformation [23], and no work has been published to study the impact on EBM processed material. Previous work has confirmed residual stress concentration near the substrate interface. [14] Other work has calculated geometric deformation in LM parts, demonstrating the usefulness of using FEA tools for studying AM processes [24]. Due to the higher operating temperature of the EBM process (approximately $1000^{\circ} \mathrm{C}$ for Inconel 718 ), modeling work is important to better understand this phenomenon.

\section{$\underline{\text { Motivation }}$}

Using an Arcam EBM system, Inconel builds were fabricated at the Manufacturing Demonstration Facility (MDF) at the Oak Ridge National Laboratory (ORNL), TN. Warping in the base plate was observed in some cases, causing the build to have irregular layers near the base plate. In a few cases, difficulties to proceed to the next layers were faced due to excessive deformation of the base plate. In order to avoid such setbacks during the EBM process, computational models that are able to predict such mechanical behavior a priori are useful to developing and implementing solutions.

The paper is organized in the following sections: A brief description of the EBM process is presented first, followed by the computational model description and the material system used. Then, thermal and stress analyses conducted are described. Finally, a qualitative comparison of deformation and residual stress influence are discussed, followed by conclusions.

\section{Electron Beam Melting Process}

Tensile test coupons are fabricated on stainless steel base plate using the Electron Beam Melting (EBM) process in an Arcam EBM system (refer to Fig. 1). In-situ thermocouple measurements of temperature during the EBM process are determined at the center of the bottom surface of the base plate. Fig. 1(b) shows the "start plate" made of steel, which is also referred to as "base plate", "build plate" or "build substrate" in this article. A machine log file generator is used to compile the readings 
from this thermocouple to obtain the temperature-time plot. The thermal cycle shown in Fig. 2 is a typical thermal profile of an EBM process as reported by Sames et al. [6]. Typically, a thermal profile can be split into the following stages: (1) Initial heating and outgassing; (2) Sintering of powder under the substrate; (3) Layer melting and (4) Cool down, as shown in Fig. 2.

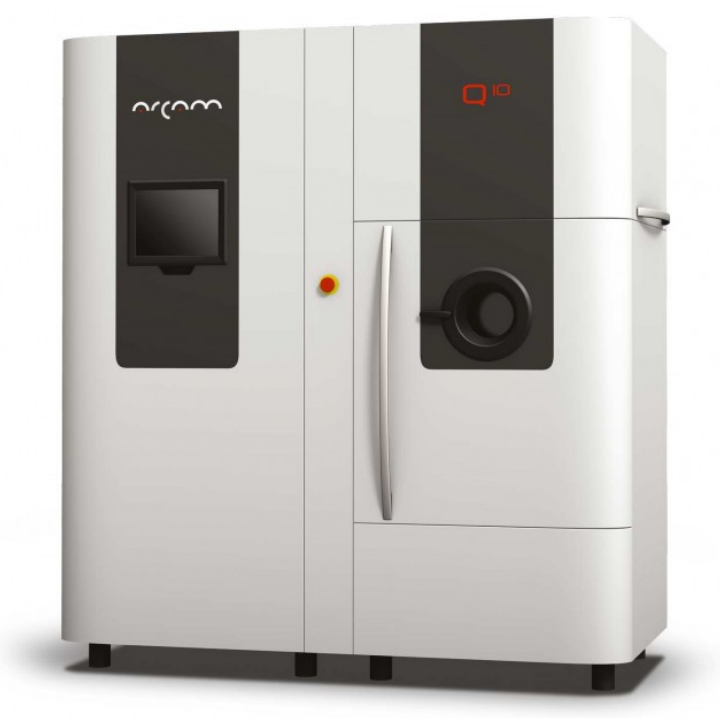

(a)

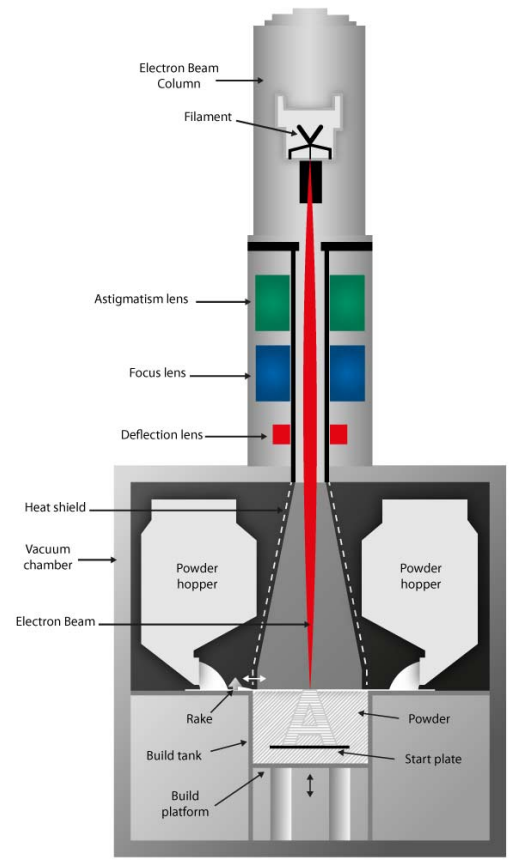

(b)

Figure 1: Arcam Q10 EBM machine and (b) Schematic of EBM setup (Photo source: Arcam website)

An experimentally obtained temperature profile for the fabricated coupon build at the center of the bottom surface of the base plate is shown in Fig. 3, which is approximated in this paper for modeling purposes as shown in Fig. 5. The corresponding experimental parameters are listed here: Number of layers $=266$ layers $(19.95 \mathrm{~mm}$ total height processed); Layer thickness $=75 \mu \mathrm{m}$; Software: EBM Control 4.1.22; Process time: $4 \mathrm{hr}$, $44 \mathrm{~min}$; Cool down time: $4 \mathrm{hr}, 53 \mathrm{~min}$ (helium injected, fast cool); Input Current $=15 \mathrm{~mA}$ (actual current varies according to geometry); Speed Function $=50$; Max Current $=22 \mathrm{~mA}$. 


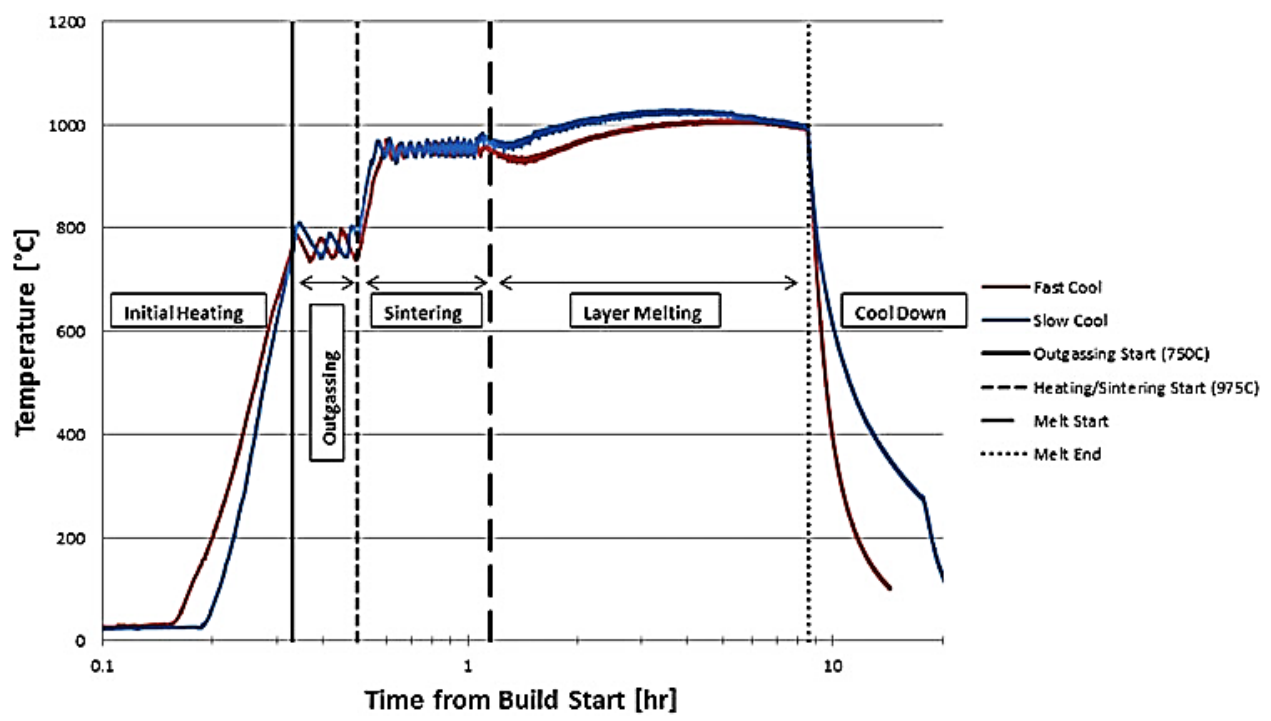

Figure 2: Typical temperature profile obtained during an EBM process (Photo source: [6])

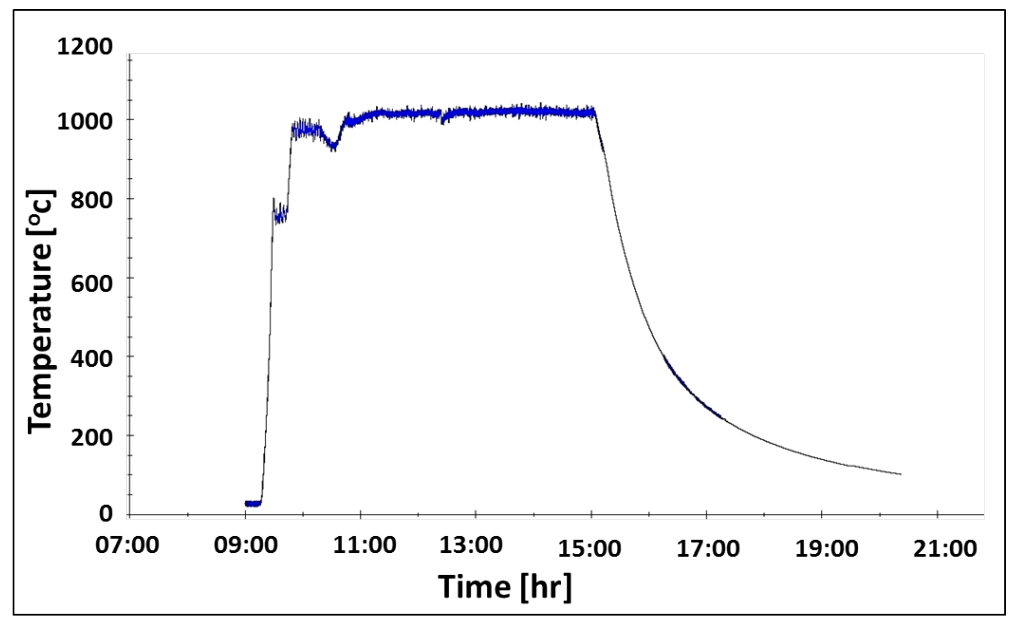

Figure 3: Experimentally determined temperature profile of the EBM process

\section{Computational Model}

The computational model considered for this study is a build with tensile test coupons as shown in Fig. 4. The build consists of a Inconel 718 powder bed (red region), a stainless steel base plate (blue region) and six Inconel 718 coupons (green region). The base plate is sintered into the powder bed, as shown in Fig. 4(a). The coupon dimensions are $8 \mathrm{~cm} \times 1.8 \mathrm{~cm} \times 2 \mathrm{~cm}$, and the dimension of the base plate are $15 \mathrm{~cm}$ x $15 \mathrm{~cm}$ x $1 \mathrm{~cm}$. For clarity, Fig. 4(b) displays only the tensile test coupons and 
the base plate.

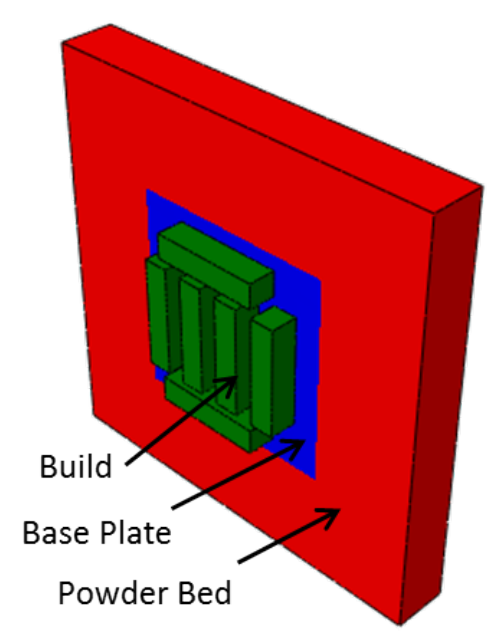

(a)

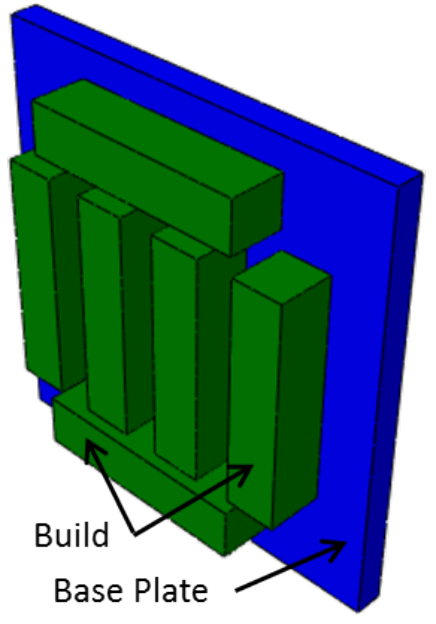

(b)

Figure 4: Tensile test coupon build model (a) with powder bed and (b) without powder bed

A layer by layer model for the coupon build with 50 layers is constructed using commercially available finite element analysis (FEA) software (ABAQUS 6.12) to simulate the EBM process. A thermal analysis is conducted first to determine the temperature distribution within the model, followed by a structural analysis to determine the stress, strain and deformation caused due to the heat imparted to the model during the EBM process. Details of the material properties used, the thermal and the stress analyses conducted are given in the following sections.

\section{Material System}

The properties of Inconel 718, stainless steel and the sintered powder are given in this section. The heat transfer analysis requires the variation of properties like, density, thermal conductivity and specific heat capacity of the three materials with temperature. Further, for the structural analysis an elastic-plastic behavior for the the build and the base plate is assumed. Therefore, the properties required are the elastic modulus, Poisson's ratio, yield stress, hardening behavior and the coefficient of thermal expansion variation with temperature. 
Table 1: Thermo-physical properties

\begin{tabular}{c|ll|ll|ll}
\hline \hline & \multicolumn{2}{|l|}{ Inconel $718[25]$} & \multicolumn{2}{l|}{ Stainless Steel[25] } & \multicolumn{2}{l}{ Powder Bed (Assumed) } \\
\hline Temperature $\left({ }^{\circ} \mathrm{C}\right)$ & 126 & 1126 & 126 & 1126 & 126 & 1126 \\
\hline Density $\left(\mathrm{kg} / \mathrm{m}^{3}\right)$ & 8200 & 7850 & 7775 & 7300 & 4100 & 3925 \\
\hline Thermal Conductivity $(\mathrm{W} / \mathrm{m}-\mathrm{K})$ & 12.0 & 30 & 18 & 40 & 0.036 & 0.09 \\
\hline Specific Heat Capacity $(\mathrm{J} / \mathrm{kg}-\mathrm{K})$ & 460 & 720 & 490 & 620 & 460 & 720 \\
\hline
\end{tabular}

The thermo-physical and mechanical properties used in the model are given in Table 1 and Table 2, respectively.

Table 2: Mechanical properties

\begin{tabular}{c|ll|ll|ll}
\hline \hline & \multicolumn{2}{|l|}{ Inconel } & 718 & {$[26,27]$} & Stainless Steel $[26,27]$ & \multicolumn{2}{l}{ Powder Bed (Assumed) } \\
\hline Temperature $\left({ }^{\circ} \mathrm{C}\right)$ & 93 & 760 & 20 & 500 & 25 & 500 \\
\hline Elastic Modulus $(\mathrm{GPa})$ & 205 & 162 & 200 & 165 & 20 & 12 \\
\hline Poisson's Ratio & 0.3 & 0.3 & 0.28 & 0.28 & 0.1 & 0.1 \\
\hline Yield Stress (MPa) & 1172 & 758 & 215 & 122 & - & - \\
\hline Hardening Coefficient & 0.637 & 0.637 & 0.206 & 0.206 & - & - \\
\hline Coeff. of Thermal Expansion $\left(/{ }^{\circ} \mathrm{C}\right)$ & $12.8 \mathrm{e}-6$ & $16 \mathrm{e}-6$ & $16 \mathrm{e}-6$ & $18 \mathrm{e}-6$ & $6 \mathrm{e}-6$ & $8 \mathrm{e}-6$ \\
\hline
\end{tabular}

\section{Thermal Analysis}

The thermal analysis consists of a heat transfer problem to be solved to determine the spatial and temporal distribution of temperature during the EBM process. Towards that, layer-by-layer heat transfer is conducted in this paper. That is, uniform heat is applied to a layer, and the transfer of heat to the subsequent layers is determined. Though, the scanning strategies influence the temperature profile in the build, modeling every scan line is extremely expensive in terms of computational time. This is because extremely small elements with size comparable to the scan line width are required to apply heat along a line in the model. Also, since the layer creation is a fast process, the distribution of temperature is assumed to be uniform in the plane perpendicular to the build direction, and the transfer of heat along the build direction is focused here. Therefore, a layer-by-layer heat transfer study is adopted in this paper.

An overall temperature profile for fabricating the build is shown in Fig. 5 (a), which is an approximation of the experimentally determined profile shown in Fig. 3. The ini- 
tially linear region is an approximation for the initial heating, outgassing and sintering stages of the EBM process. The flat region represents the temperature profile during the build step, followed by an exponentially reducing cool down region. A temperature profile for a period of 40 seconds shown in Fig. 5 (b) is imparted on each layer of the build that accounts for the scan and raking time. The maximum temperature applied on each layer of the build is $1500^{\circ} \mathrm{C}$. The base plate is assumed to be at an initial temperature of $1000^{\circ} \mathrm{C}$, i.e., the thermal analysis starts post sintering and simulates the layer building steps of the EBM process followed by cooling (refer to Fig. 2). Though Fig. 2 shows that the maximum temperature recorded during the EBM process is around $1000^{\circ} \mathrm{C}$, it corresponds to the center of the bottom surface of the base plate, and does not reflect the temperature of the layers being built. In the model, a lower temperature than that expected during the EBM process is assumed to be applied on each of the layers, since it does not account for radiation effects from the surface.

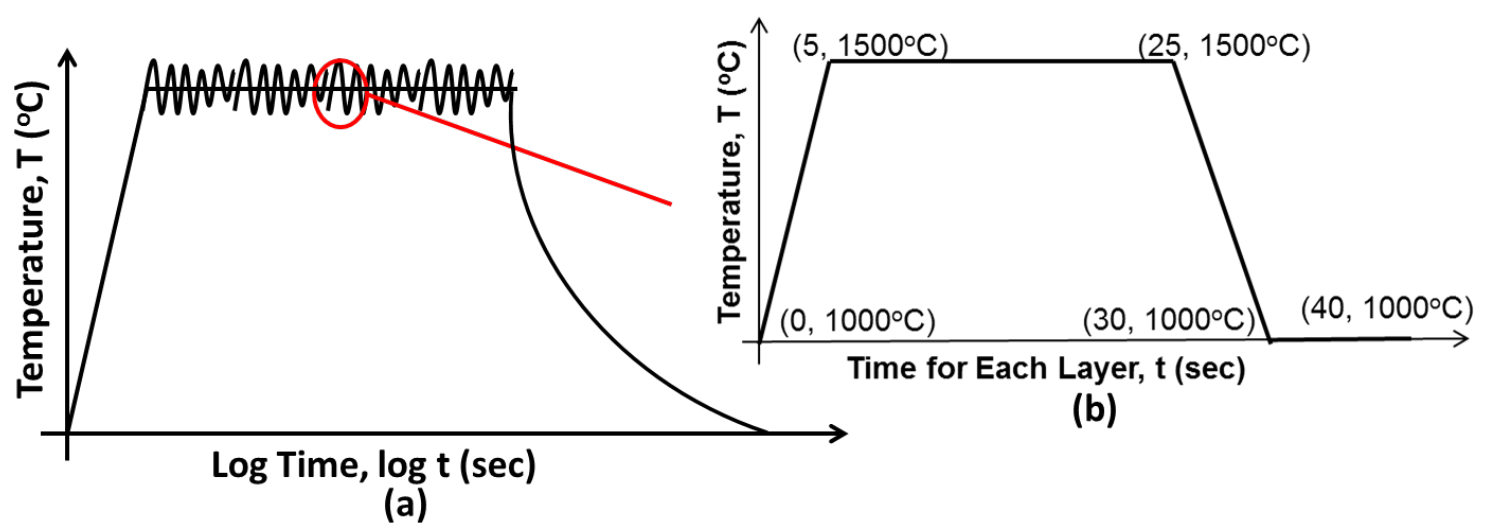

Figure 5: Temperature profile applied to the model during the EBM process

From the first law of thermodynamics, the heat equation accounting for the heat generated and conducted is given by, 


$$
\begin{array}{r}
\rho c_{p} \frac{\partial T}{\partial t}=\frac{\partial}{\partial x}\left(K \frac{\partial T}{\partial x}\right) \\
T=1000^{\circ} C @ t=0, \forall \Omega_{\text {baseplate }} \& \Omega_{\text {powderbed }} \\
T=T_{a p}\left(t_{l}\right) \text { for } t_{l}=\left(0, t_{\text {layer }}\right) ; \text { where }, l=1, n
\end{array}
$$

where, $T_{a p}$ is the temperature applied on each layer during the layer building process (shown in Fig. 5(b)) and ' $n$ ' is the total number of build layers. The external boundaries of the powder bed are considered to be adiabatic, assuming complete insulation from the external environment. The spatial and temporal distribution of temperature in the entire system for the complete period of the EBM process is determined.
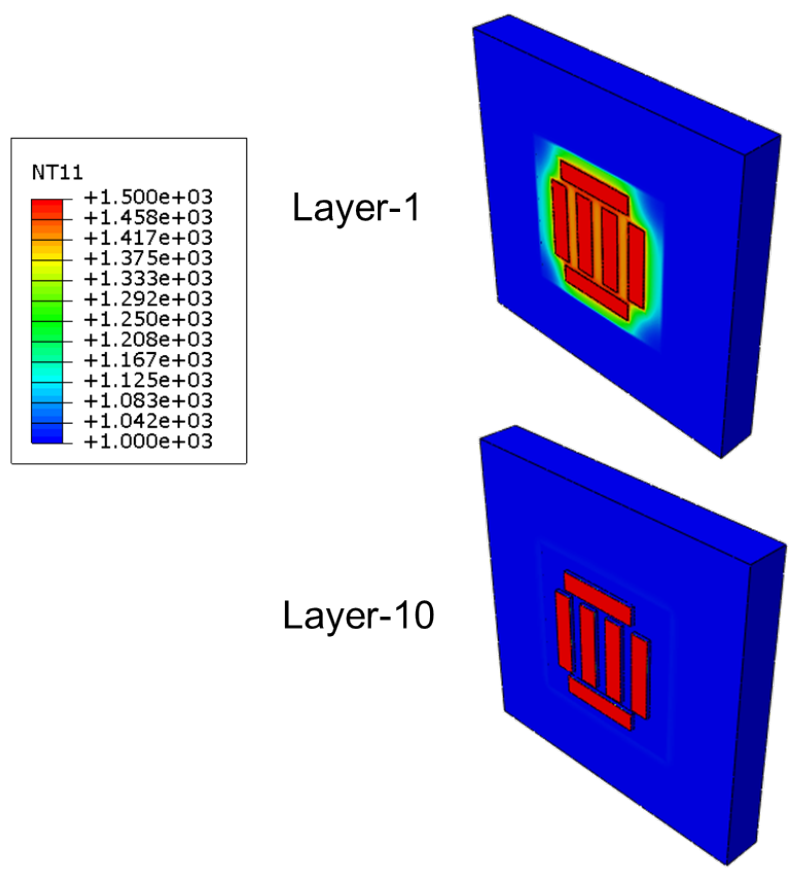

\section{Layer-4}

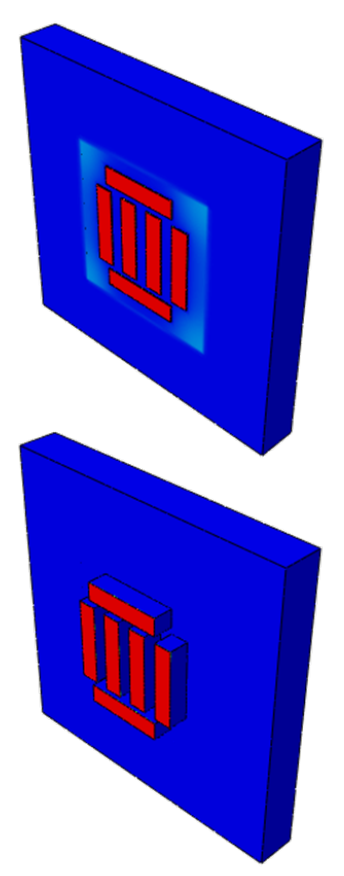

Figure 6: Spatial and temporal temperature distribution map on the build layers, base plate and powderbed

The temperature distribution in the model corresponding to the completion of different number of layers is shown in Fig. 6. It is observed that the influence of temperature applied on the layers to the base plate reduces as the layers are built up. This implies 
that the thermal impact is restricted to a few top layers of the build with reduced influence on the base plate as shown in Fig. 6.

\section{Stress Analysis}

The temperature distribution in the model for the entire process obtained from the thermal analysis is then applied to the model in order to conduct the stress analysis. Again, a layer-by-layer analysis is conducted to investigate the influence of the heat applied during the EBM process on the stress, strain and deformation in the model.

The equilibrium equation shown below is solved numerically within the FEM framework to determine the displacement field in the model for the temperature field and mechanical boundary conditions applied.

$$
\begin{array}{r}
\frac{\partial \sigma}{\partial \mathbf{x}}+f=0 \\
u_{1}=0 @ x_{1}=0 ; u_{1}=0 @ x_{1}=L \\
u_{2}=0 @ x_{2}=0 ; u_{2}=0 @ x_{2}=W \\
u_{3}=0 @ x_{3}=0
\end{array}
$$

where, $u_{i}, i=1,2,3$ are the displacements in the $\mathrm{x}, \mathrm{y}$ and $\mathrm{z}$-directions, $L$ and $W$ are the dimensions of the powder bed in the $\mathrm{x}$ and $\mathrm{y}$-directions, respectively. The bottom of the powder bed $\left(x_{3}=0\right)$ is fixed $\left(u_{3}=0\right)$ in the $\mathrm{z}$-direction, which implies that there is wall beneath the powder bed. Also, this boundary condition has a far-field effect on the stresses and deformation of the base plate as it is sufficiently far from the bottom of the powder bed. The fixed boundary conditions are applied on the external faces of the powder bed, and not on the base plate or the build. Therefore, the base plate is resting in a bed of sintered Inconel 718 powder and its deformation is influenced by the powderbed around it and the corresponding temperature distribution. A schematic of the mechanical boundary conditions are shown in Fig. 7, where the walls (constrained 
surfaces) are indicated.

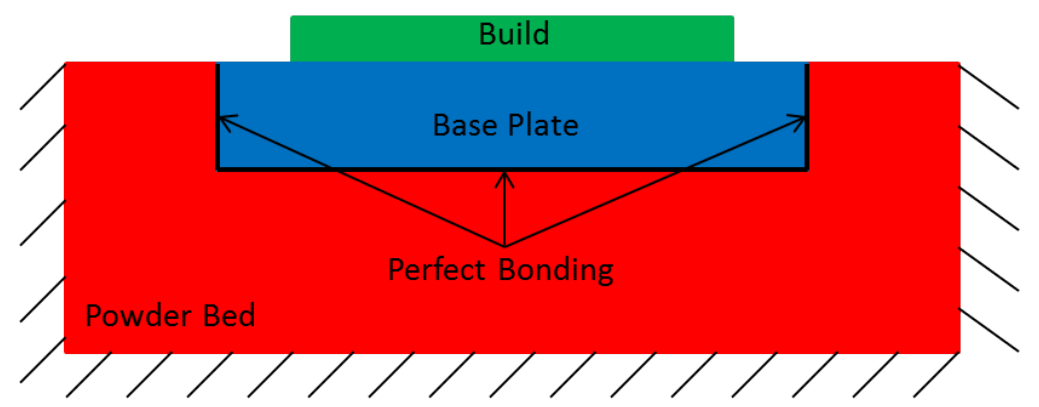

Figure 7: Boundary conditions for stress analysis

The equivalent plastic strain and Von Mises stress accumulated on the top and bottom faces of the base plate corresponding to point 5 in Fig. 9 are plotted in Fig. 8 . Stresses and plastic strain accumulation in the base plate appear to be high towards the end of the EBM process, which indicate that the coupons obtained will be deformed. Therefore, the quality of the coupons are affected by the warping of the base plate during the EBM process.
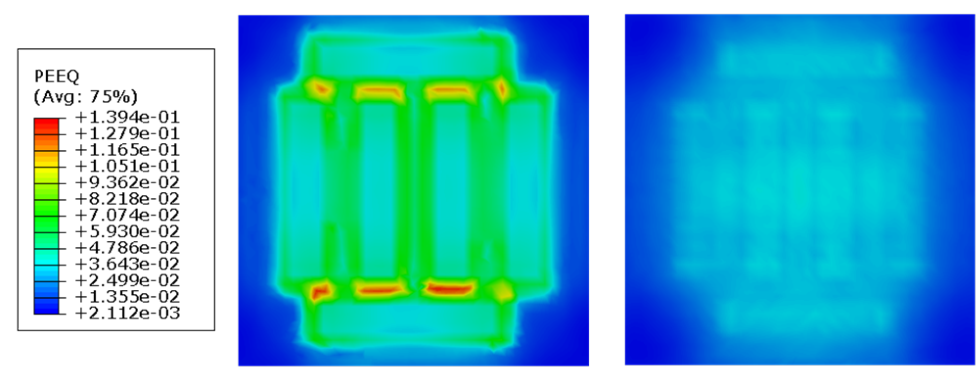

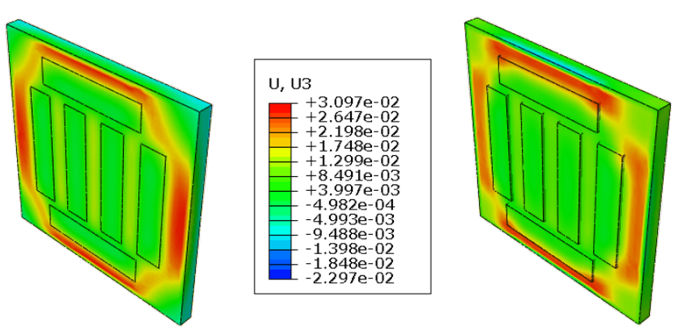

Log Time, log t (sec)
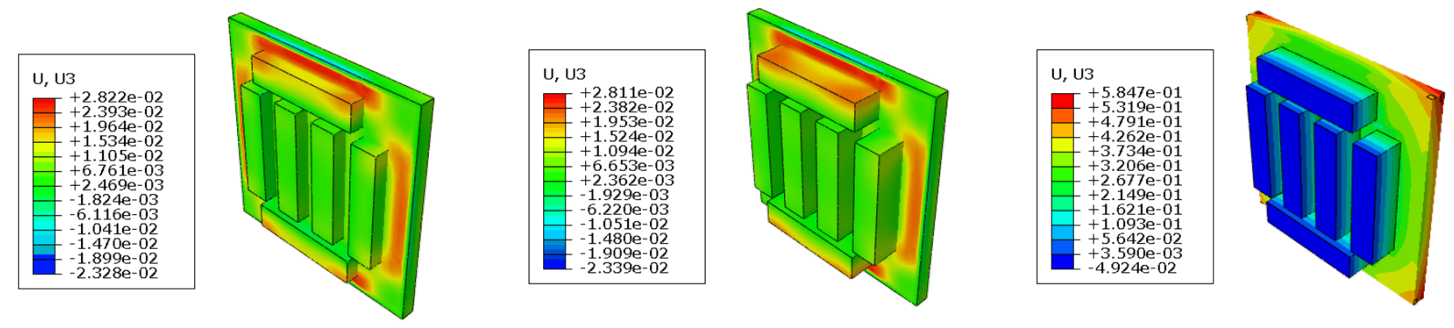

Figure 9: Deformation of the base plate with build at different times

The deformation of the base plate along with the build is shown in Fig. 9 at different times that correspond to different number of layers built on the base plate. It is observed that the top face of the base plate bulges upward during the build process. The red regions around the build represent higher extent of the bulge compared to the builds, which implies that there is a warping in the plate that causes the coupons to be deformed. The bulge in the base plate reduces with increasing number of layers of the build, hinting that the layers built later are less deformed that the initial layers of the build. After cool down there is a permanent upward warp in the base plate. Therefore, the bottom layers in the build are warped more than the upper layers. Similar behavior is observed experimentally during the EBM process with stainless steel base plate.

\section{Qualitative Comparison of Deformation}

A qualitative comparison of the deformation of the base plate and the coupon build is conducted in this section. Plate deflection observed in the computational model is qualitatively similar to the one observed in the experiments. Warping in the base plate is captured using the computational method proposed in this paper, where the corners warp upward leaving the central region to form a trough. Deformed shape of the base 
plate with build towards the end of the fabrication process is shown in Fig. 10.

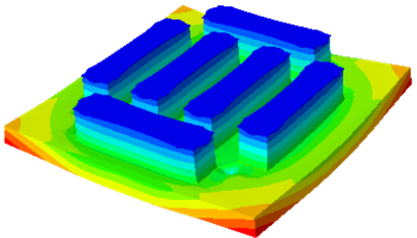

(a)

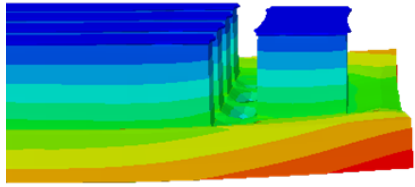

(b)

Figure 10: Computational results of tensile test coupon build showing the effects of warping

Deformation in the plate and the build obtained experimentally are shown in Fig. 11, where an overall warping of the base plate is observed (Fig. 11(a)). A closer view of the build, shown in Fig. 11(b), indicates that the build layers in the vicinity of the base plate are warped, but they tend to get even away from the base plate as the build progresses.

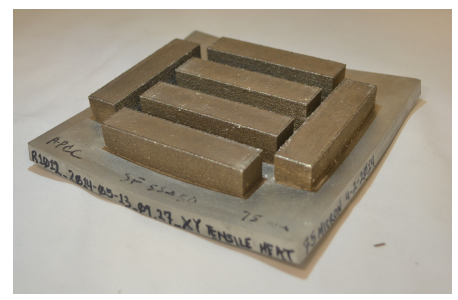

(a)

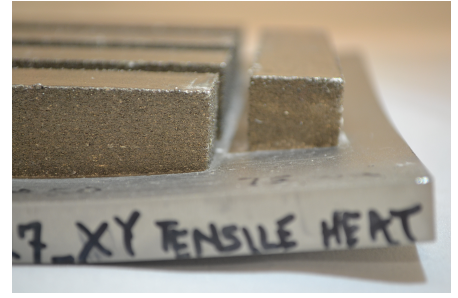

(b)

Figure 11: Tensile test coupon build showing the effects of warping

It is hypothesized that the warping of the base plate occurs during the building of the initial few layers, due to the intensity of the electron beam. Influence of the beam on the base plate reduces as the build progresses away from the base plate. The extent of warping further increases during the cool down process and is influenced by the rate of cooling as well as difference in cooling of the build and the base plate. It is observed in the computational model (Fig. 10) that the edges surrounding the build appear to warp causing the bottom layers to warp as well. Therefore, measures should be taken during the initial layer building stages as well as the cool down step of the EBM process 
to avoid any such significant warping in the base plate from occurring. Few suggestions to reduce the accumulation of residual stresses in the base plate are as follows: (a) Increase the thickness of the base plate to reduce it's warping; (b) Choose a base plate made of the same material as the build material; (c) Increase the temperature of the base plate and powderbed during the initial outgassing and sintering stages prior to layer building; (d) Choose a gradual cool down rate at the beginning followed by an exponential decay.

\section{Conclusion}

In this paper, a computational modeling approach to simulate the EBM process within an Arcam machine is developed. A layer-by-layer model is constructed, and thermal and stress analyses are conducted within the FEA framework to determine the deformation and stresses in the build and the base plate. Warping in the base plate and the initial layers of the build was observed post the EBM process. It was observed that the warping in the base plate and the build occurred during the construction of the first few layers using the computational model. Further, significant warping was also observed during the cool down step. Computational model predictions were qualitatively comparable to the deformations observed in the base plate and the build manufactured using EBM.

Such a modeling approach has a potential to aid in understanding the behavior of the manufactured components during the EBM process. Undesired process conditions can be eliminated if the deformation observed during the simulation of the process is excessive and could potentially result in bad build or process. Therefore, the modeling approach presented in this paper can be used as a design tool to minimize the trial and error associated with the EBM process. 


\section{Acknowledgements}

Research sponsored by the U.S. Department of Energy, Office of Energy Efficiency and Renewable Energy, Advanced Manufacturing Office, under contract DE-AC0500OR22725 with UT-Battelle, LLC. This research was also supported by fellowship funding received from the U.S. Department of Energy, Office of Nuclear Energy, Nuclear Energy University Programs. The United States Government retains and the publisher, by accepting the article for publication, acknowledges that the United States Government retains a non-exclusive, paid-up, irrevocable, world-wide license to publish or reproduce the published form of this manuscript, or allow others to do so, for United States Government purposes.

This manuscript has been authored by UT-Battelle, LLC under Contract No. DEAC05-00OR22725 with the U.S. Department of Energy. The United States Government retains and the publisher, by accepting the article for publication, acknowledges that the United States Government retains a non-exclusive, paid-up, irrevocable, world-wide license to publish or reproduce the published form of this manuscript, or allow others to do so, for United States Government purposes. The Department of Energy will provide public access to these results of federally sponsored research in accordance with the DOE Public Access Plan (http://energy.gov/downloads/doe-public-access-plan). For additional information regarding publications and the DOE Public Access Plan, visit the Publications Tracking System website.

We would also like to thank ORNL HBCU/MEI summer faculty opportunity 2014 for enabling the research presented in this paper. We would also like to acknowledge The University of Texas at El Paso for enabling this opportunity with ORNL.

\section{References}

[1] K.N. Amato, S.M. Gaytan, L.E. Murr, E. Martinez, P.W. Shindo, J. Hernandez, S. Collins, and F. Medina. Microstructures and mechanical behavior of inconel 718 fabricated by selective laser melting. Acta Materialia, 60:22292239, 2012.

[2] Lawrence E. Murr, Edwin Martinez, Krista N. Amato, Sara M. Gaytan, Jennifer Hernandez, Diana A. Ramirez, Patrick W. Shindo, Frank Medina, and Ryan B. Wicker. Fabrica- 
tion of metal and alloy components by additive manufacturing: Examples of 3d materials science. Journal of Materials Research and Technology, 1(1):42 - 54, 2012. ISSN 2238-7854. doi: http://dx.doi.org/10.1016/S2238-7854(12)70009-1.

[3] Y. Tian, D. McAllister, H. Colijn, M. Mills, D. Farson, M. Nordin, and S. Babu. Rationalization of microstructure heterogeneity in inconel 718 builds made by the direct laser additive manufacturing process. Metallurgical and Materials Transactions A, 45(10):4470-4483, 2014. ISSN 1073-5623. doi: 10.1007/s11661-014-2370-6.

[4] Z. Wang, K. Guan, M. Gao, X. Li, X. Chen, and X. Zeng. The microstructure and mechanical properties of deposited-in718 by selective laser melting. Journal of Alloys and Compounds, 513 (0):518 - 523, 2012. ISSN 0925-8388. doi: http://dx.doi.org/10.1016/j.jallcom.2011.10.107.

[5] A. Strondl, M. Palm, J. Gnauk, and G. Frommeyer. Microstructure and mechanical properties of nickel based superalloy in718 produced by rapid prototyping with electron beam melting (ebm). Materials Science and Technology, 27:876 - 883, 2011.

[6] W. J. Sames, K. A. Unocic, R. R. Dehoff, T. Lolla, and S. S. Babu. Thermal effects on microstructural heterogeneity of inconel 718 materials fabricated by electron beam melting. Journal of Materials Research, 2014 (Accepted).

[7] K. A. Unocic, L. M. Kolbus, R. R. Dehoff, S. N. Dryepondt, and B. A. Pint. High-temperature performance of n07718 processed by additive manufacturing. NACE Corrosion 2014, San Antonio, $T X$.

[8] R. Dehoff, C. Duty, W. Peter, Y. Yamamoto, C. Wei, C. Blue, and C. Tallman. Case study: Additive manufacturing of aerospace brackets. Advanced Materials \& Processes, 171:19 - 22, 2013.

[9] D. D. Gu, W. Meiners, K. Wissenbach, and R. Poprawe. Laser additive manufacturing of metallic components: materials, processes and mechanisms. International Materials Reviews, 57:133 $164,2012$.

[10] A. Chaudhary. Modeling of laser-additive manufacturing processes. ASM Handbook, 22B:240 $252,2010$.

[11] C. Zhang, L. Li, and A. Deceuster. Thermomechanical analysis of multi-bead pulsed laser power deposition of a nickel-based superalloy. Journal of Materials Processing Technology, 211:1478 $1487,2011$.

[12] H. Qi, M. Azer, and A. Ritter. Studies of standard heat treatment effects on microstructure and mechanical properties of laser net shape manufactured inconel 718. Metall. Mater. Trans. A., 40: $2410-2422,2009$.

[13] X. Zhao, J. Chen, X. Lin, and W. Huang. Study on microstructure and mechanical properties of laser rapid forming inconel 718. Materials Science and Engineering A, 478:119 - 124, 2008.

[14] F. Liu, X. Lin, C. Huang, M. Song, G. Yang, J. Chen, and W. Huang. The effect of laser scanning path on microstructures and mechanical properties of laser solid formed nickel-base superalloy inconel 718. Journal of Alloys and Compounds, 509:4505 - 4509, 2011.

[15] Y. Zhang, Z. Li, P. Nie, and Y. Wu. Effect of heat treatment on niobium segregation of lasercladded in718 alloy coating. Metall. Mater. Trans. A, 44A:706 - 718, 2013. 
[16] I. Tabernero, A. Lamikiz, S. Martinez, E. Ukar, and J. Figuerasu. Evaluation of the mechanical properties of inconel 718 components built by laser cladding. International Journal of Machine Tools \& Manufacture, 51:456 - 470, 2011.

[17] S. S. Al-Bermani, M. L. Blackmore, W. Zhang, and I. Todd. The origin of microstructural diversity, texture, and mechanical properties in electron beam melted ti-6al-4v. Metallurgical and Materials Transactions A, 41A(0):3422 - 3434, 2010.

[18] P. Mercelis and J.-P. Kruth. Residual stresses in selective laser sintering and selective laser melting. Rapid Prototyping Journal, 12:254 - 265, 2006.

[19] T. Gnupel-Herold, J. Slotwinski, and S. Moylan. Neutron measurements of stresses in a test artifact produced by laser-based additive manufacturing. AIP Conference Proceedings, 1581:1205 $-1212,2014$.

[20] P. Rangaswamy, T. M. Holden, R. B. Rogge, and M. L. Griffith. Residual stresses in components formed by the laser-engineered net shaping (lens \& reg) process. Journal of Strain Analysis for Engineering Design, 38:519 - 527, 2003.

[21] L. M. Sochalski-Kolbus, E. A. Payzant, P. A. Cornwell, T. R. Watkins, S. S. Babu, R. R. Dehoff, and et al. Comparison of residual stresses in inconel 718 simple parts made by electron beam melting and direct laser metal sintering. Metallurgical and Materials Transactions A, 2014. (submitted).

[22] A. Wu, M. M. LeBlanc, M. Kumar, G. F. Gallegos, D. W. Brown, and W. E. King. Effect of laser scanning pattern and build direction in additive manufacturing on anisotropy, porosity and residual stress. 2014 TMS Annual Meeting \&3 Exhibition, San Diego, CA, 2014.

[23] J. Ding, P. Colegrove, J. Mehnen, S. Ganguly, P.M. Sequeira Almeida, F. Wang, and S. Williams. Thermo-mechanical analysis of wire and arc additive layer manufacturing process on large multilayer parts. Computational Materials Science, 50(12):3315 - 3322, 2011. ISSN 0927-0256. doi: http://dx.doi.org/10.1016/j.commatsci.2011.06.023.

[24] M. Zaeh and G. Branner. Investigations on residual stresses and deformations in selective laser melting. Production Engineering, 4(1):35-45, 2010. ISSN 0944-6524.

[25] COMSOL materials library [Inconel 718 (UNS N07718); Stainless Steel 304 (UNS S30400 solid polished)].

[26] Inconel 718 technical data. High Temp Metals. URL http://www .hightempmetals.com.

[27] Elevated temperature physical properties of stainless steels. BS EN 10088-1. URL http://www.bssa.org.uk/topics . php?article=139. 